\title{
How integrated is the world economy?
}

\author{
Harry P. Bowen · Haris Munandar • \\ Jean-Marie Viaene
}

Published online: 20 June 2010

(C) The Author(s) 2010. This article is published with open access at Springerlink.com

\begin{abstract}
This paper develops a methodology to measure the degree of economic integration between nations that are members of an integrated area. We show that a fully integrated economic area (IEA) is characterized by three properties regarding the distribution of member shares of total IEA output and total IEA stocks of physical and human capital. We then show that the expected distribution of member shares within a fully IEA is a harmonic series, with the share distribution depending only on the number of IEA members. This property is then used to develop a composite indicator of the degree of economic integration within an IEA that indicates the distance between the theoretical and actual distribution of shares: the closer is the actual distribution to the expected distribution, the greater the degree of integration. We empirically compute our degree of integration for US states, and alternative regional trading agreements (e.g., EU countries, MERCOSUR, Bangkok Agreement, etc.) and a "world" comprising 64 countries.
\end{abstract}

Keywords Distribution of production - Economic convergence . Factor mobility · Economic integration

\section{H. P. Bowen}

McColl School of Business, Queens University of Charlotte, 1900 Selwyn Avenue, Charlotte, NC 28274, USA

e-mail: bowenh@queens.edu

H. Munandar

Central Bank of Indonesia and University of Indonesia,

Jl. M.H. Thamrin No. 2, Jakarta 10350, Indonesia

e-mail: hmunandar@bi.go.id

J.-M. Viaene $(\bowtie)$

Erasmus University Rotterdam, Tinbergen Institute and CESifo,

P.O. Box 1738, 3000 DR Rotterdam, The Netherlands

e-mail: viaene@ese.eur.nl 
JEL Classification $\quad \mathrm{E} 13 \cdot \mathrm{F} 15 \cdot \mathrm{F} 21 \cdot \mathrm{F} 22 \cdot \mathrm{O} 57$

\section{Introduction}

The past decade has witnessed a surge of negotiating activity around regional trade agreements (RTAs) as numerous subsets of countries have sought deeper integration among themselves. The WTO expects close to 400 RTAs to be implemented by 2010. ${ }^{1}$ To date, the most notable examples of RTAs include NAFTA (United States, Canada and Mexico), the accession of 12 additional countries into the European Union (EU), and MERCOSUR. However, there are several ongoing efforts to initiate or renew agreements among a variety of nations (e.g., Free Trade for the Americas, ASEAN). On average, each trading nation is currently a member of six preferential agreements. However, the typical developed country of the Northern hemisphere is on average a member of 13 agreements (World Bank 2005). Geographically, free trade initiatives are unevenly distributed across various parts of the world. Regional economic integration has come late to East Asia, but its pace has accelerated since the creation of the WTO.

The present "spaghetti bowl" of preferential treatments is a complex web of treaties and rules whose prospects for a reallocation of global production are fundamental, but not yet fully understood (Bhagwati 2002). The potential for greater mobility of productive factors within any given integrated area is increasingly powerful, not only because cross-border factor flows are becoming more important, ${ }^{2}$ but also because the international trade literature has long recognized that cross-border factor flows and trade in goods and services can be substitutes (Mundell 1957) or complements (Markusen 1983). Hence, reduced barriers to the movement of goods and of productive factors within a RTA would be expected to affect the final distribution of production across RTA members. Since integration is multidimensional, the measurement of its intensity is a challenging issue of considerable importance. This paper is an attempt at developing such a methodology.

Quantification of the degree of economic integration within an integrated area generates fresh insights into a number of critical questions. First, it is important to evaluate integration efforts of major existing RTAs and to observe how these evolve through time. Second, it allows for a comparison of the degree of economic integration across different RTAs since the coverage and depth of preferential treatments vary from one agreement to the other. For example, some RTAs involve only traditional tariff-cutting policies while others include rules on e.g. services, competition, investment and migration, and further institutional arrangements like the European Monetary Union to adopt a single currency. The economic union of the United States is perhaps the most sophisticated form of integration, with

\footnotetext{
${ }^{1}$ See the WTO website for an update of existing and planned free trade initiatives.

${ }^{2}$ The importance of factor mobility in many parts of the world is evidenced by the growing importance in many nations' balance of payments of remittances from abroad (e.g., International Monetary Fund 2004). Capital flows in the form of foreign direct investment continue to be important among industrialized countries and they are increasingly also being directed toward developing countries.
} 
member states unifying all economic and socio-economic policies. As a rule, it is believed in policy circles that the degree of integration increases with the intensity of policy harmonization. Finally, assessing the degree of economic integration for the world as a whole serves to quantify the effects of globalization. On the one hand, most WTO liberalization initiatives that emerged from the Uruguay Round went into force only in the mid-1990s. On the other hand, the architecture of a RTA is discriminatory since member countries seek to eliminate trade barriers among themselves but maintain those on imports from non-member countries, with numerous rules of origin also usually imposed to prevent the free movement of goods even within a RTA.

Several empirical studies estimate the extent of economic integration by openness, often measured by the ratio of trade to GDP. Greenaway et al. (2001) extend these proxies to construct the so-called index of extended intra-industry trade that can distinguish between penetration of a market due to increased imports versus increased production by domestic affiliates of foreign companies. However, a trade measure is a narrow indicator of the changes brought about by a RTA, and for this reason broader measures of globalization have also been estimated. For example, Andersen and Herbertsson (2003) use factor analysis to combine several variables believed to be indicators of globalization into a single indicator. Riezman et al. (2005, 2006) use applied general equilibrium techniques to compute alternative metrics of the distance between free trade, autarky and observed (restricted) trade equilibria. Our point of departure relative to this literature is that we seek to measure the degree of integration within a given RTA. In addition, we consider forms of integration that are deeper than "globalization" in that the latter is considered a liberalization process that leads to "a reduction in the barriers-whether technological or legislative-to economic exchanges between nations" (Ethier 2002). Our analysis expands on this to include also economic and socio-economic policy coordination.

Our indicator of the degree of integration measures the distance between observed values (shares) of output and factor stocks across RTA members and the values (shares) expected theoretically to emerge within a fully integrated economic area (IEA), the latter being an integrated area in which goods and factors are freely mobile and policies are harmonized. The theoretical foundation of our indicator uses the cross-country equalization of factor marginal products as the force driving the allocation of resources across IEA members, and we combine this with the latest developments regarding the increasingly observed empirical regularity of Zipf's law in economic data (e.g., Gabaix 2008). Our framework yields three related theoretical predictions. The first is that factor mobility among members of an IEA implies that each member's share of total IEA output will equal its shares of the total IEA stock of each productive factor (i.e., its shares of total IEA physical and human capital). We call this theoretical outcome the "equal-share" relationship. The second prediction is that the distribution of output and productive factors across IEA members is expected to exhibit Zipf's law; ${ }^{3}$ this law establishes a specific

\footnotetext{
3 Other recent theoretical and empirical contributions show Zipf's law to be an empirical regularity in international trade. For example, Hinloopen and van Marrewijk (2006) find that the Balassa index of comparative advantage obeys to the rank-size rule, and very often to Zipf's law. Also, the size distribution of exporters analyzed in Helpman et al. (2004) conforms roughly to Zipf's law.
} 
relationship among member shares of output and productive factors, namely, that the e.g. output share of the largest member is twice that of the second largest member, three times that of the third largest member, etc. Of course, the question arises as to why Zipf's law will occur. In the literature, a central mechanism for the emergence of Zipf's law is random growth of shares, and similarly our explanation builds on the random nature of output and factor shares that arises from policy harmonization within an IEA. In this setting, we apply the results of Gabaix (1999) to infer that if IEA member shares evolve as geometric Brownian motion with a lower bound, then the limiting distribution of these shares will exhibit Zipf's law. Thirdly, if Zipf's law holds, we show that the expected distribution of shares within an IEA is a harmonic series, where the shares of this series depend only on the number of IEA members. This allows us to derive, for an IEA of fixed size, the expected distribution of shares across IEA members. The closer the actual distribution of shares is from this expected distribution the greater the degree of integration within the given IEA. Our measure of the degree of economic integration reflects therefore the distance between expected and actual distributions.

Given the potential importance of our metrics for future integration policies, we empirically compute our measures of integration for the 50 US states and the District of Columbia (hereafter called the 51 US states) and for different RTAs (e.g., EU countries, Andean Community, MERCOSUR, Latin American Integration Association, and Bangkok Agreement) and a "world" comprising 64 countries. 4 The data generally cover the period from 1965 to 2000 .

The remainder of the paper is as follows. Section 2 derives the theoretical properties of a fully integrated economic area with respect to the distribution of output and factors across IEA members and the expectation that member shares of IEA output and factors will evolve randomly. Section 3 discusses the implications of this randomness for the long-run distribution of output and factors across IEA members and the expectation that member shares will conform to a rank-share distribution that exhibits Zipf's law. Section 4 computes the theoretical shares and describes the data used to measure actual shares of our economic groups. Section 5 provides a weak test of the equal-share relationship. Section 6 defines our integration measures and computes these measures for alternative economic groups. Section 7 summarizes and discusses the consequences of our findings. An Appendix discusses data methods and sources.

\section{Equality of output and factor shares}

We consider an economy (or economic unit) that produces a single good by means of a constant return to scale production function:

\footnotetext{
4 This is the scenario dreamed of by ideological organizations like the Global Awareness Society International (GASI): "Globalization has made possible what was once merely a vision: the peoples of our world united under the roof of one Global Village". See the GASI website, originally cited in Rodrik (1997).
} 


$$
Y_{t}=F\left(K_{t}, H_{t}\right)
$$

where $Y_{t}$ is the level of output, $K_{t}$ is the level of physical capital stock and $H_{t}$ is the level of human capital stock, all at time $t$. To facilitate interpretation we assume the production function takes the Constant Elasticity of Substitution (CES) form:

$$
Y_{t}=\gamma\left\{\delta K_{t}^{-\rho}+(1-\delta) H_{t}^{-\rho}\right\}^{-1 / \rho}
$$

where $\gamma$ is an efficiency parameter, $\delta$ the degree of physical capital usage, and $\rho$ is a substitution parameter such that the elasticity of substitution between the two inputs is $\sigma=1 /(1+\rho)$. Given (2), the marginal product of physical capital is:

$$
F_{K t}=\gamma \delta\left\{\delta+(1-\delta)\left(\frac{K_{t}}{H_{t}}\right)^{\rho}\right\}^{-(1+\rho) / \rho}
$$

Combining (2) and (3) one can write:

$$
F_{K t}=\gamma^{-\rho} \delta\left(\frac{Y_{t}}{K_{t}}\right)^{1+\rho}
$$

Similarly, the marginal product of effective labor (human capital) is:

$$
F_{H t}=\gamma(1-\delta)\left\{(1-\delta)+\delta\left(\frac{K_{t}}{H_{t}}\right)^{\rho}\right\}^{-(1+\rho) / \rho}
$$

or

$$
F_{H t}=\gamma^{-\rho}(1-\delta)\left(\frac{Y_{t}}{H_{t}}\right)^{1+\rho}
$$

We now introduce a second economy and consider the implications of allowing factor mobility between the two economies. We assume initially that the two countries share a common technology. Later in Sect. 4, we will extend our analysis to allow for technological differences and also discuss the implications of other assumptions.

Assuming perfect mobility of physical and human capital between the two economies, and that goods are freely traded, we expect each factor to flow from the low-return to the high-return country until its marginal product is equalized between the two economies. For our IEA comprising two countries, this equality in real rates of return can be written:

$$
\begin{gathered}
\gamma^{-\rho} \delta\left(\frac{Y_{t}}{K_{t}}\right)^{1+\rho}=\gamma^{-\rho} \delta\left(\frac{Y_{t}^{*}}{K_{t}^{*}}\right)^{1+\rho} \\
\gamma^{-\rho}(1-\delta)\left(\frac{Y_{t}}{H_{t}}\right)^{1+\rho}=\gamma^{-\rho}(1-\delta)\left(\frac{Y_{t}^{*}}{H_{t}^{*}}\right)^{1+\rho}
\end{gathered}
$$

where ' $*$ ' indicates second economy variables. Due to the assumption of identical technologies, these expressions imply equality of average factor productivities (the inverse of unit factor requirements): 


$$
\begin{aligned}
\frac{Y_{t}}{K_{t}} & =\frac{Y_{t}^{*}}{K_{t}^{*}} \\
\frac{Y_{t}}{H_{t}} & =\frac{Y_{t}^{*}}{H_{t}^{*}}
\end{aligned}
$$

Traditionally, the magnitudes in (9) and (10) serve as a basis for productivity calculations and comparisons across countries. However, unlike the existing literature (e.g., Hall and Jones 1999) where productivity is measured by output per worker, Eq. (10) for human capital expresses (like in the endogenous growth literature) productivity in terms of output per effective unit of labor.

We are now fully equipped to illustrate the implications of the model for the distribution of output and factors between the two economies. To obtain a first expression of our key relationship we note first that the ratio of (9) to (10) yields an equality between ratios of human to physical capital:

$$
\frac{H_{t}}{K_{t}}=\frac{H_{t}^{*}}{K_{t}^{*}}
$$

Since a common scaling of the levels of each factor in each country will leave the ratios in (11) unchanged, the equality of factor ratios in (11) implies also their equality to the ratio of the sum of their numerator terms to the sum of their denominator terms:

$$
\frac{H_{t}}{K_{t}}=\frac{H_{t}^{*}}{K_{t}^{*}}=\frac{H_{t}+H_{t}^{*}}{K_{t}+K_{t}^{*}}
$$

Similarly, the equality of ratios in (9) implies:

$$
\frac{Y_{t}}{K_{t}}=\frac{Y_{t}^{*}}{K_{t}^{*}}=\frac{Y_{t}+Y_{t}^{*}}{K_{t}+K_{t}^{*}}
$$

Together, Eqs. (12) and (13) imply the following set of equalities:

$$
\frac{H_{t}}{H_{t}+H_{t}^{*}}=\frac{Y_{t}}{Y_{t}+Y_{t}^{*}}=\frac{K_{t}}{K_{t}+K_{t}^{*}}
$$

Relationship (14) indicates the distribution of factors and economic activity between the two economies of our IEA. Specifically, when technologies are identical and there are no barriers to factor mobility, each economy's shares of total IEA output, physical capital and human capital will be identical. We hereafter call (14) the equal-share relationship. ${ }^{5}$

Relationship (14) extends easily to an IEA with $l=1, \ldots, N$ members. Specifically, if all members have the same technology and there is perfect mobility of physical and human capital among members then the equalization of factor rates of return implies:

\footnotetext{
5 Our framework also relates to the broad topic of output convergence since, if the equal-share relationship holds, it is clear that the two economies will have the same output per efficiency unit of labor. This implication is the essence of the productivity convergence hypothesis (Barro and Sala-ì-Martin 2004), here interpreted in terms of efficiency units of labor and not per capita.
} 


$$
\frac{H_{n t}}{\sum_{l=1}^{N} H_{l t}}=\frac{Y_{n t}}{\sum_{l=1}^{N} Y_{l t}}=\frac{K_{n t}}{\sum_{l=1}^{N} K_{l t}} \quad n=1, \ldots, N
$$

or $S_{n H t}=S_{n Y t}=S_{n K t}$ in compact form, where $S_{n j t}$ represents member $n$ 's share of the total IEA amount of variable $j(j=Y, K$, or $H)$ at date $t$.

The equal-share relationship (15) has implications regarding the relative economic performance of IEA members. For example, consider a reallocation of physical capital among IEA members that leaves the total IEA stock of capital unchanged. From (15), any country that gains physical capital will experience an increase in the return to human capital and hence will accumulate human capital either on its own, or through an inflow of human capital from those IEA members whose physical capital was reduced. An IEA member that gains physical and human capital will subsequently increase its output, and hence also its share of total IEA output, to reestablish the equality of its output and factor shares as in (15). By the same reasoning, an inflow of foreign direct investment into one IEA member will increase that member's share of total IEA physical capital and its return to human capital, ultimately raising the country's share of total IEA human capital and total IEA output.

In addition to insights regarding the effects of factor accumulation on the distribution of output among IEA members, Eq. (15) offers a key insight on the effects of pursuing coordinated versus independent policies within an IEA. To understand this, assume that IEA member $n$ increases its human capital by a factor $\lambda$. It then follows from (15) that, as described above, this member's shares of total IEA physical capital and total IEA output will also increase. In contrast, if all IEA members increase their human capital by the common factor $\lambda$ then all shares would remain the same. This suggests that the more harmonized (coordinated) are the economic policies of IEA members the more likely are member shares to be stable over time with, in the extreme, full harmonization implying that members' shares are constant over time. In this case, any change over time in members' shares would arise only from random events such as innovation, resource discovery, natural disasters, civil unrest, etc. Since randomness of members' shares is more likely the greater the extent of economic and socio-economic integration among members, such randomness is more likely if members do not run independent monetary or exchange rate policies, fiscal policies are constrained by institutions, education systems are harmonized, and successful local industrial policies are rapidly imitated. Accepting that changes in output and factor shares in a fully integrated economy will occur randomly, the question then arises as to the implications of this randomness for the long-run distribution of economic activity across IEA members. This is the subject of the next section.

\section{Long-run distribution of activity}

Our interest in the long-run distribution of activity within a fully integrated economic area is that it can serve as the benchmark for measuring the extent of integration within a given IEA. Toward this end, we adapt the specification and results of Gabaix (1999) to our setting to derive the implications of random shares 
for the long-run distribution of economic activity within an IEA. Specifically, Gabaix shows (his Proposition 1) that if the city shares of a nation's population evolve randomly as geometric Brownian motion with an infinitesimal lower bound then the steady state distribution of these shares will be a rank-size distribution that exhibits the property known as Zipf's law. This law implies the existence of a relationship between the values of a given variable (share) and the rank number of these values. This means, for example, that the population share of a nation's second largest city will be one-half of the population share of its largest (first ranked) city.

Translating Gabaix's (1999) result to our framework requires the assumption that the evolution of an IEA member's output and factor shares can be approximated by a geometric Brownian motion with a lower bound. Formally, this assumes that the growth over time in the shares of member $n$ is captured by the following dynamic process:

$$
\frac{d S_{n j t}}{S_{n j t}}=\mu d t+\sigma d B_{t}
$$

In this expression, $S_{n j t}>\min \left(S_{n j t}\right)$ is member $n$ 's share of variable $j(j=Y, K, H)$ where $\min \left(S_{n j t}\right)$ is the lower bound, $B_{t}$ is a Wiener process, ${ }^{6} \mu$ is a drift parameter, and $\sigma$ is the standard deviation of the distribution of shares. As in Gabaix, the distribution of the growth rates of shares is assumed to be common to all IEA members; this translates to assuming that the values of $\mu$ and $\sigma$ are common to all IEA members. The specification of Brownian motion in (16) is only one of many ways to model random dynamics, but it has the property of being parsimonious in terms of number of parameters. The assumption of a lower bound on shares seems realistic in our context since important income transfers are institutionalized to prevent states/regions/countries from vanishing: relief programs are in place in case of disasters like a tsunami; the EU maintains a social fund and a regional fund. ${ }^{7}$

Accepting the above characterization for random shares, Gabaix's (1999) results allow us to conclude that the long-run distributions of IEA members' output and factor shares will exhibit Zipf's law. In our context, Zipf's law implies the following relationship between the share values $S_{n j t}$ for a particular variable $j(j=Y, K, H)$ and their rank number across IEA members:

$$
S_{n j t}=\gamma_{j t}\left(R_{n j t}\right)^{-1} \quad n=1, \ldots, N ; j=Y, K, H .
$$

In this expression, $R_{n j t}$ denotes the rank number of share value $S_{n j t}$ at time $t$, obtained by ranking shares $S_{n j t}$ in descending order and assigning rank number $R_{n j t}=1$ to the largest share value. Given this, Eq. (17) implies a specific relationship among

\footnotetext{
${ }^{6}$ The term $d B_{t}$ is the increment of the process. It is defined in continuous time as $d B_{t}=\varepsilon_{t}(d t)^{1 / 2}$, where $\varepsilon_{t}$ is a stochastic term with zero mean and unit standard deviation, implying $\mathrm{E}\left[d B_{t}\right]=0$ and $\operatorname{Var}\left(d B_{t}\right)=d t$. In discrete time, one needs to approximate the increment $d B_{t}$. A possibility is to assume one or more shocks for each of the 365 calendar days of a year $(d t=1 / 365)$, in which case $d B_{t}$ is the running sum over all discrete increments ("shocks"). The drift $\mu$ is expected to be zero since the sum over $n$ of the output and factor shares must be one. The standard deviation $\sigma$ can be estimated using past and current observations.

7 Technically, the assumption of a lower bound on the output and factors shares is needed to obtain a power law distribution since, otherwise, the steady state distribution of shares would be lognormal.
} 
shares, namely, $S_{1 j t} / S_{2 j t}=2, S_{1 j t} / S_{3 j t}=3, S_{1 j t} / S_{4 j t}=4$, etc. Hence, as noted earlier, Zipf's law implies that the share value of the highest ranked (largest) economy is twice the share value of the second ranked economy, three times the share value of the third ranked economy, etc.

Equation (17) provides the foundation for deriving the expected or long-run distribution of shares within a fully integrated economy. First, note that (17) implies that $S_{n j t}=\gamma_{j t}$ for the first ranked country $\left(R_{n j t}=1\right)$ and hence that the constant $\gamma_{j t}$ $\left(0<\gamma_{j t}<1\right)$ is the share of variable $j$ for the highest ranked IEA member. In turn, this result has implications for the equal-share relationship. Specifically, if $\gamma_{Y t}=\gamma_{K t}=\gamma_{H t}$ then by definition the equal-share relationship holds for the largest IEA member. Given this, the proportional relationship indicated in (17) between any member's share and the share of largest IEA member (e.g., $\left.S_{2 j t}=S_{1 j t} / 2\right)$ then implies that the equal-share relationship also holds for each of the remaining IEA members.

Besides the association between share values and their rank number as indicated by (17), it is possible to completely characterize the distribution of shares in a given IEA by exploiting the fact that the number of economies in a given IEA is finite and known. To show this, let $V_{n j t}$ denote the level of variable $j$ for member $n$ and assume without loss of generality that member 1 has the largest value of variable $j$. Define $\delta_{n j t}$ as the ratio between member $n$ 's value of variable $j$ and the value of variable $j$ for member 1 at date $t$ (i.e., $\delta_{n j t}=V_{n j t} / V_{l j t}$ ). Now order the values of variable $j$ in descending order. Since $\delta_{1 j t}=1$, this descending ordering of the values of variable $j$ across the $n=1, \ldots, N$ members can be written:

$$
V_{1 j t}>\delta_{2 j t} V_{1 j t}>\delta_{3 j t} V_{1 j t}>\cdots>\delta_{N j t} V_{1 j t}, \quad j=Y, K, H .
$$

Since the total IEA amount of variable $j$ is $\left(1+\delta_{2 j t}+\delta_{3 j t}+\cdots+\delta_{N j t}\right) V_{1 j t}$, Eq. (18) implies the following relations between member ranks and shares:

$$
\begin{aligned}
\text { Rank 1: } & S_{1 j t}=\frac{1}{1+\delta_{2 j t}+\delta_{3 j t}+\cdots+\delta_{N j t}} ; \\
\text { Rank 2: } & S_{2 j t}=\frac{\delta_{2 j t}}{1+\delta_{2 j t}+\delta_{3 j t}+\cdots+\delta_{N j t} t} \\
\text { Rank 3: } & S_{3 j t}=\frac{\delta_{3 j t}}{1+\delta_{2 j t}+\delta_{3 j t}+\cdots+\delta_{N j t}} ; \\
\vdots & \vdots \\
\text { Rank } \mathrm{N}: & S_{N j t}=\frac{\delta_{N j t}}{1+\delta_{2 j t}+\delta_{3 j t}+\cdots+\delta_{N j t}} .
\end{aligned}
$$

Equation (19) indicate that the ordered sequence of shares $S_{n j t}$ is a harmonic series, where each share value $S_{n j t}$ depends on the value of the $\delta$ 's and the number of members $N$. These expressions imply a specific relationship among shares: $S_{1 j t} /$ $S_{2 j t}=\delta_{2 j t}^{-1}, S_{1 j t} / S_{3 j t}=\delta_{3 j t}^{-1}, S_{1 j t} / S_{4 j t}=\delta_{4 j t}^{-1}$, etc. Since the number of countries in a given IEA is known, knowing the values of the $\delta$ s is sufficient to fully characterize this harmonic series. However, Eq. (17) characterizing Zipf's law also establishes a relationship among shares, namely, $\delta_{1 j t}=1, \delta_{2 j t}=2^{-1}, \delta_{3 j t}=3^{-1}, \delta_{4 j t}=4^{-1}$, etc. If the rank-share relationship (17) is constant (stable) over time then the $\delta$ s will also be constant (stable) over time, in which case the harmonic series in (19) can be 
interpreted as a long-run relationship. We therefore denote the long-run theoretical shares by $\bar{S}_{n j}$ and drop the time subscript.

\section{Data}

Having identified the long-run properties of a fully integrated economic area we are now able to construct the necessary values for our integration metrics. For each presumably integrated area, we consider two sets of data:

$$
\begin{array}{r}
\text { Theoretical shares } \bar{S}_{1 j}, \bar{S}_{2 j}, \ldots, \bar{S}_{N j} \quad j=Y, K, H \\
\text { Actual shares } S_{1 j t}, S_{2 j t}, \ldots, S_{N j t} \quad j=Y, K, H .
\end{array}
$$

Given this, this section discusses the construction of these two share distributions for alternative economic groups. In particular, we consider the various regional trade agreements listed in Table 1. Our focus is on agreements that (i) are relatively old since their effects are supposedly imbedded in the data, and (ii) are of sufficient size to obtain enough observations. We limit our sample of RTAs to those having at least four countries.

\begin{tabular}{|c|c|}
\hline Economic group (start date) & Member countries \\
\hline United States of America & 50 US States + District of Columbia \\
\hline European Union (EU-14, 1975) & $\begin{array}{l}\text { Austria, Belgium-Luxembourg, Denmark, Finland, France, } \\
\text { Germany, Greece, Ireland, Italy, Netherlands, Portugal, Spain, } \\
\text { Sweden, United Kingdom }\end{array}$ \\
\hline Andean Community (CAN, 1969) & Bolivia, Columbia, Ecuador, Peru, Venezuela \\
\hline $\begin{array}{l}\text { Southern Common Market } \\
\text { (MERCOSUR, 1991) }\end{array}$ & Argentina, Brazil, Paraguay, Uruguay \\
\hline $\begin{array}{l}\text { Latin American Integration } \\
\text { Association (LAIA, 1980) }\end{array}$ & $\mathrm{CAN}+\mathrm{MERCOSUR}+\mathrm{Cuba}$ \\
\hline $\begin{array}{l}\text { Bangkok Agreement (Bangkok, } \\
\text { 1975) }\end{array}$ & Bangladesh, China, India, Republic of Korea, Laos, Sri Lanka \\
\hline $\begin{array}{l}\text { Southern African Customs Union } \\
\quad(\text { SACU, 1910) }\end{array}$ & Botswana, Lesotho, Namibia, South Africa, Swaziland \\
\hline $\begin{array}{l}\text { Southern African Development } \\
\text { Community (SADC, 1980) }\end{array}$ & $\begin{array}{l}\text { SACU + Angola, Mozambique, Mauritius, Malawi, Tanzania, } \\
\text { Zambia, Zimbabwe }\end{array}$ \\
\hline World-64 & $\begin{array}{l}\text { All countries above }+ \text { Australia, Canada, Chile, Dominican } \\
\text { Republic, Guatemala, Honduras, Hong Kong, Iceland, Iran, } \\
\text { Israel, Jamaica, Japan, Kenya, Mexico, New Zealand, Norway, } \\
\text { Panama, Philippines, Sierra Leone, Switzerland, Syria, Taiwan, } \\
\text { Thailand, Turkey, United States }\end{array}$ \\
\hline
\end{tabular}

Table 1 Economic groups

\subsection{Theoretical shares}

As indicated in the previous section, the theoretical result that the long-run distribution of shares in a fully integrated economic area will exhibit Zipf's law 
Table 2 Distribution of theoretical shares

\begin{tabular}{|c|c|}
\hline Economic group & Theoretical shares (descending) \\
\hline US States & $\begin{array}{l}0.2213,0.1106,0.0738,0.0553,0.0443,0.0369,0.0316,0.0277,0.0246 \\
0.0221,0.0201,0.0184,0.0170,0.0158,0.0148,0.0138,0.0130 \\
0.0123,0.0116,0.0111,0.0105,0.0101,0.0096,0.0092,0.0089 \\
0.0085,0.0082,0.0079,0.0076,0.0074,0.0071,0.0069,0.0067 \\
0.0065,0.0063,0.0061,0.0060,0.0058,0.0057,0.0055,0.0054 \\
0.0053,0.0051,0.0050,0.0049,0.0048,0.0047,0.0046,0.0045 \\
0.0044,0.0043\end{array}$ \\
\hline EU-14 & $\begin{array}{l}0.3075,0.1538,0.1025,0.0769,0.0615,0.0513,0.0439,0.0384,0.0342 \\
0.0308,0.0280,0.0256,0.0237,0.0220\end{array}$ \\
\hline Andean Community & $0.4380,0.2190,0.1460,0.1095,0.0876$ \\
\hline MERCOSUR & $0.4800,0.2400,0.1600,0.1200$ \\
\hline $\begin{array}{l}\text { Latin American Integration } \\
\text { Association }\end{array}$ & $\begin{array}{l}0.3414,0.1707,0.1138,0.0854,0.0683,0.0569,0.0488,0.0427,0.0379 \\
\quad 0.0341\end{array}$ \\
\hline Bangkok Agreement & $0.4082,0.2041,0.1361,0.1020,0.0816,0.0680$ \\
\hline $\begin{array}{l}\text { Southern African Customs } \\
\text { Union }\end{array}$ & $0.4380,0.2190,0.1460,0.1095,0.0876$ \\
\hline $\begin{array}{l}\text { Southern African } \\
\text { Development Community }\end{array}$ & $\begin{array}{l}0.3222,0.1611,0.1074,0.0806,0.0644,0.0537,0.0460,0.0403,0.0358 \\
0.0322,0.0293,0.0269\end{array}$ \\
\hline World-64 & $\begin{array}{l}0.2108,0.1054,0.0703,0.0527,0.0422,0.0351,0.0301,0.0263,0.0234 \\
0.0211,0.0192,0.0176,0.0162,0.0151,0.0141,0.0132,0.0124 \\
0.0117,0.0111,0.0105,0.0100,0.0096,0.0092,0.0088,0.0084 \\
0.0081,0.0078,0.0075,0.0073,0.0070,0.0068,0.0066,0.0064 \\
0.0062,0.0060,0.0059,0.0057,0.0055,0.0054,0.0053,0.0051 \\
0.0050,0.0049,0.0048,0.0047,0.0046,0.0045,0.0044,0.0043 \\
0.0042,0.0041,0.0041,0.0040,0.0039,0.0038,0.0038,0.0037 \\
0.0036,0.0036,0.0035,0.0035,0.0034,0.0033,0.0033\end{array}$ \\
\hline
\end{tabular}

means the theoretical shares in (19) can be computed once the number of members $(N)$ is specified. Specifically, Zipf's law implies that $\delta_{2 j}=1 / 2, \delta_{3 j}=1 / 3, \delta_{4 j}=1 / 4$, etc., allowing calculation of the shares in (19) for given $N$. For example, the theoretical share values for the $N=51$ US states are: $0.2213,0.1106,0.0738$, $0.0553, \ldots, 0.0043$; for the $N=14$ EU countries the theoretical share values are: $0.3075,0.1538,0.1025,0.0769, \ldots, 0.0220$; likewise for other country groupings. Table 2 gives the distribution of theoretical shares for each grouping listed in Table 1.

\subsection{Observed shares}

An interesting feature of our data set is that it contains economies at widely different stages of economic development and integration, with a varying degree of data coverage. Among several data issues, two stand out. First, compared to the existing literature, an important difference is that our approach deals with human capital (efficiency units of labor) instead of labor force. This is an additional element of difficulty in that a comparable human capital proxy is needed across countries and states, and across all periods. Human capital is multifaceted and includes a complex set of human attributes, and the stock of human capital embodied in individuals is 
therefore hard to measure accurately by any one number. Educational attainment is considered the best proxy for the component of human capital obtained at school, and a country's population having at least a secondary level of education is now standard in models of human capital formation (e.g., Barro and Lee 1993, 1996). Accordingly, we measure a country's stock of human capital as the number of persons having at least a secondary level of education. Earlier empirical studies use school enrollment ratios or literacy rates. These data are widely available but do not adequately measure the stock of human capital available as an input to production. ${ }^{8}$ The number of persons in a population who have successfully completed a given level of schooling seems a straightforward measure of the stock of human capital that reflects the attainment of skills and knowledge acquired through education. However, in practice there is significant variation across countries in the duration of each cycle of education. We therefore use the estimates in Barro (2000) which have taken into account this variation by using information on the typical duration of each level of schooling within countries.

A second difficulty is data on stocks of physical capital. While data are readily available for some countries, for those with missing data we apply the perpetual inventory method to time series on real gross capital formation. For countries lacking data on depreciation rates, we use the average of the depreciation rates of countries in the same RTA for which data are available. In what follows, we provide a brief description of the data used to construct each share value $S_{n j t}$. The Appendix provides a more complete description of the data and methods.

For each of the 51 US states, output is measured by real gross state product (GSP). The physical capital stock of each state is estimated in two steps. First, an estimate of the total US physical capital stock in an industry is multiplied by that industry's contribution to a state's total income. Second, the industry physical capital stock estimates are summed across industries to obtain an estimate of a state's total stock of physical capital. The human capital stock of each state is measured by the number of persons in the state with at least a secondary education. Due to missing data, complete data for US states on all three variables (output, physical capital and human capital) are available only for 1990 and 2000, years in which the US Decennial Census was conducted. However, output and physical capital stock data are available for other years. Where appropriate (e.g., when computing rank correlations) we use these additional years of data.

With respect to the remaining economic groups listed in Table 1, the output of each member country is measured by its real gross domestic product as reported in the Penn World Tables 6.1 (Heston et al. 2002). Country physical capital stocks from 1965 to 1990 are those reported in the Penn World Table 5.6 (Heston and Summers 1991a, b). However, data on EU country physical capital stocks for the period 1980-2000 were also available from Timmer et al. (2003). ${ }^{9}$ We combined these two data sources to obtain a capital stock series for EU countries covering

\footnotetext{
${ }^{8}$ Earlier attempts to construct a measure of educational attainment for international comparisons include Lau et al. (1991) and Nehru et al. (1995). Such measures are hindered by more limited coverage and by larger measurement errors (Barro 2000).

9 The series forms the source of the OECD productivity database. See e.g., Schreyer et al. (2003)
} 
1965-2000. ${ }^{10}$ For most countries of the developing world, time series for the stock of physical capital were constructed using the perpetual inventory method applied to time series on real gross capital formation.

Country human capital stocks are the number of persons aged 15 and over with at least a secondary education, as reported in Barro and Lee (1996, 2000). This over15 age group better corresponds to the labor force for many developing countries than does the over-25 age group used in the earlier studies of Barro and Lee (1993, 2000). However, since data on rates of educational attainment are only available every 5 years the data sample was limited to 5-year intervals from 1960 to 2000.

\section{Test of the equal-share relationship}

The equal-share predictions in Eqs. (14) and (15) are important concepts for the measurement of the extent of integration in an IEA since they provide a foundation for explaining the long-run emergence of Zipf's law with respect to output and factor shares. However, our earlier derivation of the equal-share relationship assumed economies differed only in their endowments of physical and human capital. Yet, this assumption can be questioned since the allocation of primary factors between countries may vary for other reasons.

Consider for example the case of technology differences where the parameters $\gamma$, $\delta$ and $\rho$ in (2) differ between economies. The equality of factor rates of return between two economies obtained originally in (7) and (8) can now be written:

$$
\begin{gathered}
\gamma^{-\rho} \delta\left(\frac{Y_{t}}{K_{t}}\right)^{1+\rho}=\left(\gamma^{*}\right)^{-\rho^{*}} \delta^{*}\left(\frac{Y_{t}^{*}}{K_{t}^{*}}\right)^{1+\rho^{*}} \\
\gamma^{-\rho}(1-\delta)\left(\frac{Y_{t}}{H_{t}}\right)^{1+\rho}=\left(\gamma^{*}\right)^{-\rho^{*}}\left(1-\delta^{*}\right)\left(\frac{Y_{t}^{*}}{H_{t}^{*}}\right)^{1+\rho^{*}}
\end{gathered}
$$

where ' $*$ ' indicates second economy variables. Given this, repeating the steps of Sect. 2 yields the following new expression for the equal-share relationship:

$$
\frac{H_{t}}{H_{t}+\eta\left(H_{t}^{*}\right)^{\theta}}=\frac{Y_{t}}{Y_{t}+v \omega\left(Y_{t}^{*}\right)^{\theta}}=\frac{K_{t}}{K_{t}+\left(K_{t}^{*}\right)^{\theta}}
$$

where: $\eta=\left[\delta^{*}(1-\delta) /\left(1-\delta^{*}\right) \delta\right]^{1 /(1+\rho)} ; \theta=\left(1+\rho^{*}\right) /(1+\rho) ; v=\left(\delta^{*} / \delta\right)^{1 /(1+\rho)}$; $\omega=\left[\left(\gamma^{*}\right)^{-\rho^{*}} \gamma^{\rho}\right]^{1 /(1+\rho)}$. Like (14), relationship (22) establishes a link between the first economy's shares of total IEA output, physical capital, and human capital, with differences in technology between the two economies implying a rescaling of the original variables. For example, a difference between $\gamma^{*}$ and $\gamma$ indicates a neutral difference in technologies that has no effect on the distribution of physical capital and human capital, but it does have an effect on the distribution of output through $\omega$. A difference in substitution elasticities introduces the power $\theta$ whereas differences

\footnotetext{
$\overline{10}$ We performed estimation using both sets of data for EU countries and found no qualitative difference in results when data are available from both sources (1980, 1985 and 1990). We will therefore report only the results using capital stock data from Timmer et al. (2003) during these 3 years.
} 
between the other parameters lead to a multiple rescaling of variables. The equalshare relationship in (22) simplifies to (14) when $\gamma=\gamma^{*}(\omega=1), \delta=\delta^{*}(\eta=1$, $v=1)$ and $\rho=\rho^{*}(\theta=1)$.

Deviations from (14) and (15) may arise for other reasons. For example, barriers to capital mobility may include political risk, capital controls, and tax differences that can hinder cross-border investments. Barriers to human capital mobility include government regulations on immigration and work permits, differences in pension systems and languages between countries. Such barriers to factor mobility can be analyzed by analogy to the above analysis since they introduce a wedge between marginal products. Other realistic situations could include differing endowments of natural resources, the presence of a nontradables sector, etc. Also, the adding-up constraint of shares within each group may imply a non-linear relationship among them. Given this, whether (14) and (15) are too simple to capture a complex world is a matter of empirical verification, that is, the equal-share prediction may not hold exactly but may hold in a statistical sense.

To provide an indication of the potential empirical validity of the equal-share relationship, we can examine for a "weak" form of this relationship, namely, that there will be conformity between (pair-wise) rankings of the output and factor shares across members of an economic group. Table 3 provides evidence of this weaker proposition by reporting Spearman rank correlation coefficients for pairwise rankings of the shares for each of our nine economic groups using year 2000 data. All rank correlations are positive except for SADC, and are significant in 18 of the 27 cases. High correlations are obtained for US States, Andean Community, EU14 and LAIA, indicating conformity between (pair-wise) rankings. The correlation coefficients in the first column equal unity for three of the RTAs, indicating a perfect monotone relationship between output and physical capital shares. The rank correlations involving human capital are generally lower, showing less support for the equal-share relationship. This might reflect that human capital as a primary factor is of less importance in countries with unused resources and an ill-functioning labor market.

Table 3 Spearman rank correlations for year 2000

\begin{tabular}{llll}
\hline Economic group & $\begin{array}{l}\text { Output-physical } \\
\text { capital }\end{array}$ & $\begin{array}{l}\text { Output-human } \\
\text { capital }\end{array}$ & $\begin{array}{l}\text { Human capital-physical } \\
\text { capital }\end{array}$ \\
\hline US States & $0.987^{*}$ & $0.981^{*}$ & $0.963^{*}$ \\
EU-14 & $0.956^{*}$ & $0.820^{*}$ & $0.881^{*}$ \\
Andean Community & $1.000^{*}$ & $0.900^{*}$ & $0.900^{*}$ \\
MERCOSUR & $1.000^{*}$ & 0.600 & 0.600 \\
Latin American Integration Association & $0.988^{*}$ & $0.830^{*}$ & $0.818^{*}$ \\
Bangkok Agreement & $1.000^{*}$ & 0.200 & 0.200 \\
Southern African Customs Union & 0.200 & 0.000 & 0.400 \\
Southern African Development Community & $0.661^{*}$ & -0.164 & -0.176 \\
World-64 & $0.724^{*}$ & $0.723^{*}$ & $0.464^{*}$ \\
\hline
\end{tabular}

\footnotetext{
* Indicates correlation is significantly different from zero at the $1 \%$ level
} 
Despite exceptions, these results provide support for a "weak" form of the equalshare relationship. This finding may reflect that the equalization of marginal returns between countries is not used in absolute form but is instead transformed into ratios. For example, the ratio of (9) to (10) yields the ratio of human to physical capital in (11) and, using the properties of identities of ratios, we were able to derive (14). Hence, wedges between marginal products like tariffs and transport costs, which are ignored in our theoretical model but are present in the data, tend to cancel or become weaker when ratios are used. Lastly, although the equal-share predictions (14) and (15) are not essential to our integration metrics, it is surprising to observe that RTAs with high (low) correlation coefficients in Table 3 are also those that will show a high (low) degree of integration, as indicated in the next section.

\section{Measures of economic integration}

In this section we propose measures of the level of integration within any particular grouping of countries. Ideally, it is desirable to have a single measure that summarizes the distance between the distribution of actual and theoretical shares. In probability theory, Kullback-Leibler divergence (KLD) is used to measure the difference between two probability distributions (Kullback and Leibler 1951). By analogy, KLD can be applied in our context to measure the distance between actual and theoretical share distributions. KLD is defined as:

$$
K L D\left(\bar{S}: S_{t}\right)=\frac{1}{3} \sum_{j=Y, K, H}\left(\sum_{n=1}^{N} \bar{S}_{n j} \ln \left(\frac{\bar{S}_{n j}}{S_{n j t}}\right)\right)
$$

In this formula, $S_{n j t}$ is the observed share value at time $t$ whereas $\bar{S}_{n j}$ is the timeindependent theoretical share. Values of KLD range between zero and infinity. It is zero (complete integration) when the shares are pair-wise equal, i.e., $\bar{S}_{n j}=S_{n j t}$ at date $t$ for all $n$ and $j$. Otherwise, observed deviations indicate how far a group of economies is from full integration. One drawback of the index in (23) is that it is not symmetric, in the sense that a deviation between an actual and theoretical share can be negative or positive. This means that a zero value of KLD could arise either because the distance between the shares is zero, or because the shares are equidistant around a common mean. For this reason, the following symmetric version of Kullback-Leibler divergence $(S K L D)$ is often preferred:

$$
S K L D\left(\bar{S}: S_{t}\right)=\frac{1}{3} \sum_{j=Y, K, H}\left(\sum_{n=1}^{N}\left(\bar{S}_{n j}-S_{n j t}\right) \ln \left(\frac{\bar{S}_{n j}}{S_{n j t}}\right)\right)
$$

The values of the SKLD will be higher than those of KLD because all deviations between actual and theoretical shares in the SKLD index are measured positively. Table 4 presents the computed integration indicators (23) and (24) for US states and our economic groupings listed in Table 1 using data for the year 2000. As our measures (23) and (24) indicate the extent of divergence, we also invert their values to obtain an indicator of the extent of integration rather than extent of divergence; 
Table 4 Kullback-Leibler measures for year 2000

\begin{tabular}{|c|c|c|c|c|c|}
\hline \multirow[t]{2}{*}{ Economic group } & \multicolumn{2}{|c|}{$\begin{array}{l}\text { Kullback-Leibler } \\
\text { divergence }\end{array}$} & \multicolumn{2}{|c|}{$\begin{array}{l}\text { Integration } \\
\text { indicator }^{\mathrm{a}}\end{array}$} & \multirow[t]{2}{*}{$\begin{array}{l}\text { Integration relative } \\
\text { to EU-14 }\end{array}$} \\
\hline & KLD & SKLD & I-KLD & I-SLKD & \\
\hline EU-14 & 0.050 & 0.099 & 20.00 & 10.10 & 1.00 \\
\hline US States & 0.064 & 0.125 & 15.63 & 8.00 & 0.79 \\
\hline Andean Community & 0.080 & 0.155 & 12.50 & 6.45 & 0.64 \\
\hline Latin American Integration Association & 0.132 & 0.239 & 7.58 & 4.18 & 0.41 \\
\hline Southern African Development Community & 0.418 & 0.681 & 2.39 & 1.47 & 0.15 \\
\hline Southern African Customs Union & 0.556 & 0.969 & 1.80 & 1.03 & 0.10 \\
\hline Bangkok Agreement & 0.670 & 1.018 & 1.49 & 0.98 & 0.10 \\
\hline MERCOSUR & 0.762 & 1.234 & 1.31 & 0.81 & 0.08 \\
\hline World-64 & 7.349 & 9.118 & 0.14 & 0.11 & 0.01 \\
\hline
\end{tabular}

a Inverse of (symmetric) Kullback-Leibler divergence

b Value of I-SLKD for given group relative to I-SLKD value for EU-14

the inverted values of KLD and SKLD are denoted I-KLD and I-SLKD. The last column of Table 4 lists the value of I-SLKD for each economic group relative to the value of I-SLKD obtained for the EU-14. The economic groups are listed in descending order from most to least integrated on the basis of our measures.

As Table 4 indicates, the EU-14 has the highest level of integration in year 2000. This result is surprising, in that we expected US states to show the highest level of integration. For 1990 - the other year that human capital data are available for US states - the values of I-SKLD are 9.13 for US states and 8.65 for the EU-14. Hence, in 1990, US states were slightly more integrated than the EU-14. The rise in the EU14 level of integration may reflect a variety of factors internal to the EU-14 countries. The first is German re-unification which increased Germany's observed shares such that they became closer to the theoretical predictions. Second, Ireland's independent policies aimed at increasing the country's human capital and the country's attractiveness to inflows of foreign capital led to a re-ordering of its shares. Lastly, the 1992 Single Market initiatives promoted further convergence in goods prices and factor rewards.

As indicated in the last column of Table 4, the measured level of integration of US states is about $79 \%$ that of the EU-14. The Andean Community has the third highest level of integration at about $64 \%$ of the EU-14 level. The relative level of integration of the remaining economic groups then drops sharply, with the Latin American Integration Association and the Southern African Development Community being the only groups with an integration level that is $15 \%$ or more of the level of EU-14. In this regard, the level of integration of several well-defined integrated economic areas such as MERCOSUR and Bangkok Agreement are 10\% or less the level of integration indicated for the EU-14. Finally, the "world" comprising 64 countries has the lowest level of integration with a value of about 1 percent of the value obtained for the EU-14. 
Table 5 Two-sample Kolmogorov-Smirnov $D$-statistics

\begin{tabular}{lllll}
\hline Economic group & Year & Output & Physical capital & Human capital \\
\hline US States & 1990 & 0.216 & 0.216 & 0.235 \\
EU-14 & 2000 & 0.235 & 0.275 & 0.216 \\
& 1990 & 0.357 & 0.357 & 0.214 \\
Andean Community & 2000 & 0.357 & 0.357 & 0.214 \\
& 1990 & 0.200 & 0.400 & 0.200 \\
MERCOSUR & 2000 & 0.400 & 0.400 & 0.400 \\
Latin American Integration Association & 1990 & 0.500 & 0.500 & 0.500 \\
& 2000 & 0.500 & 0.500 & 0.500 \\
Bangkok Agreement & 1990 & 0.400 & 0.500 & 0.300 \\
& 2000 & 0.500 & 0.500 & 0.300 \\
Southern African Customs Union & 1990 & 0.500 & 0.500 & 0.400 \\
Southern African Development Community & 1990 & 0.583 & 0.583 & 0.600 \\
& 2000 & 0.500 & 0.500 & 0.750 \\
World-64 & 1990 & 0.750 & 0.750 & 0.750 \\
& 2000 & 0.750 & 0.750 & 0.400 \\
& 1990 & 0.417 & 0.500 & 0.400 \\
\hline
\end{tabular}

Except for World-64, in no case is the null hypothesis that actual and theoretical shares come from the same distribution rejected at the $1 \%$ level

* Indicates $p<0.01$

While our measures do indicate the extent of the difference between theoretical and actual shares, one drawback of the Kullback-Leibler measures is that we cannot indicate if the difference in observed values is statistically significant (although we suspect the integration value computed for the "world" comprising 64 countries is significantly lower than that computed for any of the other economic groupings). Another drawback is that these measures do not indicate the extent of overall conformity of the distributions of actual and theoretical shares, that is, whether the actual and theoretical shares come from the same distribution. To address this issue, Table 5 reports values of the nonparametric two-sample Kolmogorov-Smirnov (KS) $D$-statistic which tests, for each economic grouping, whether the actual and theoretical shares come from the same distribution.

The KS test is a "goodness of fit" test whose $D$-statistic measures the maximal distance between two cumulative frequency distributions. In this test, the null hypothesis is that both sets of shares come from a common distribution against the alternative hypothesis that they do not. As the results in Table 5 indicate, we can reject the null hypothesis that actual and theoretical shares arise from the same distribution only for "World-64". This finding suggests that only relatively small 


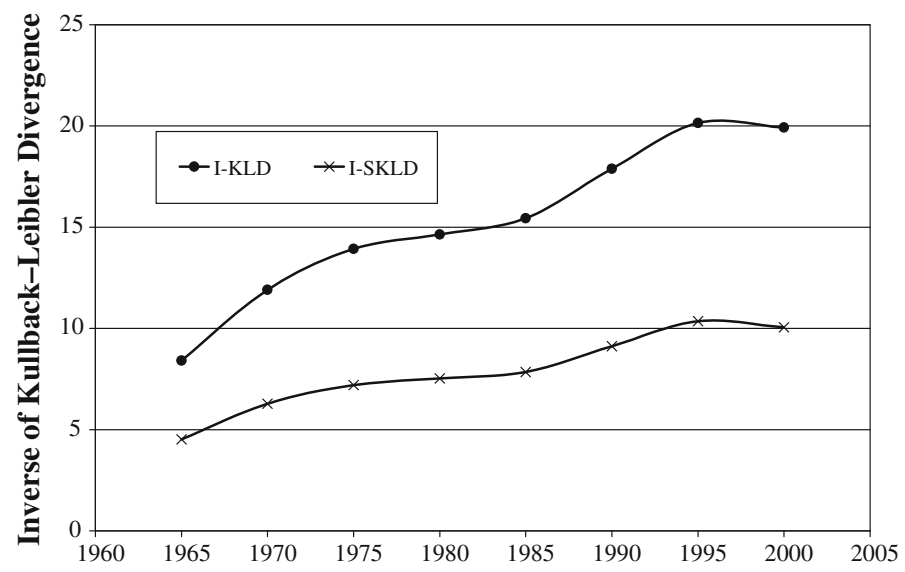

Fig. 1 Trends in integration measures, EU-14

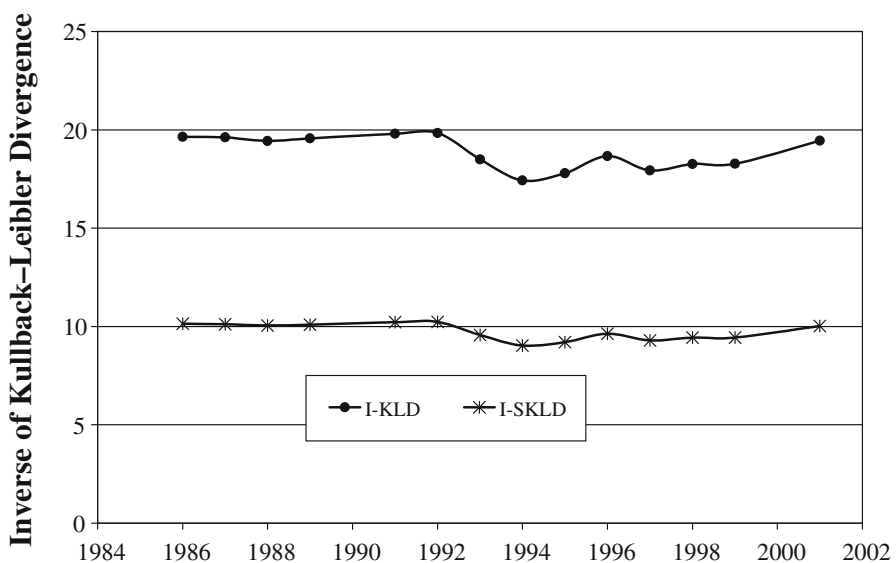

Fig. 2 Trends in integration measures, 51 US States. Measures computed using only US state output and physical capital shares due limited availability of data on state level human capital

values of our integration measures are indicative of limited integration within a given economic area. ${ }^{11}$

Figures 1, 2, 3, 4, 5, 6, 7, 8 and 9 show the values of our integration measures I-KLD and I-SKLD for each economic group at different points in time in order to visualize the trend in integration in different regions of the world. Figures 1, 5 and 6 indicate that the EU-14 and the two Africa RTAs evidence the most substantial increases in integration over time. In contrast, Fig. 2 shows the level of integration

\footnotetext{
${ }^{11}$ While popular, the Kolmogorov-Smirnov statistic is known to have low power, meaning that it more often accepts the null hypothesis when it is false (e.g., Khamis 2000). However, it is possible to compute "delta-corrected" KS statistics to assess if our results reflect the low power of the standard KS statistic (e.g., Khamis 2000).
} 


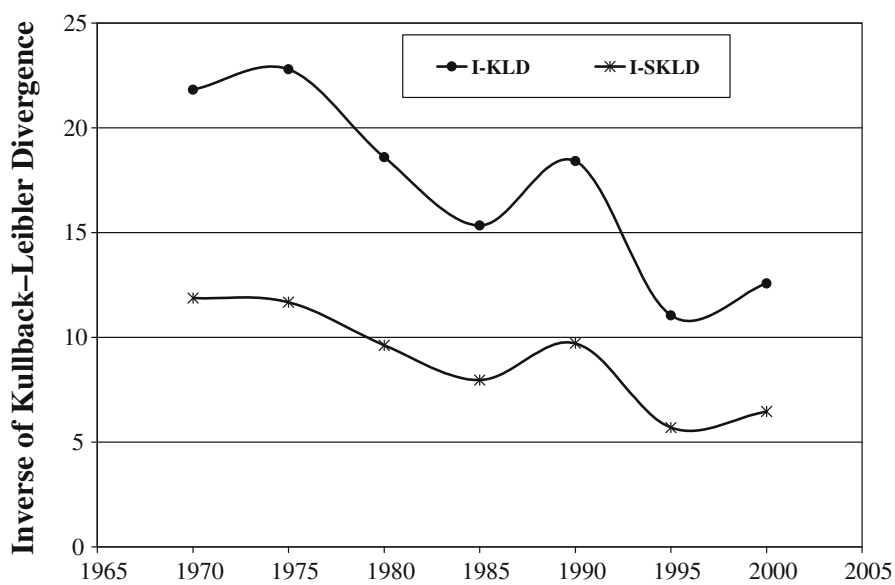

Fig. 3 Trends in integration measures, Andean Community

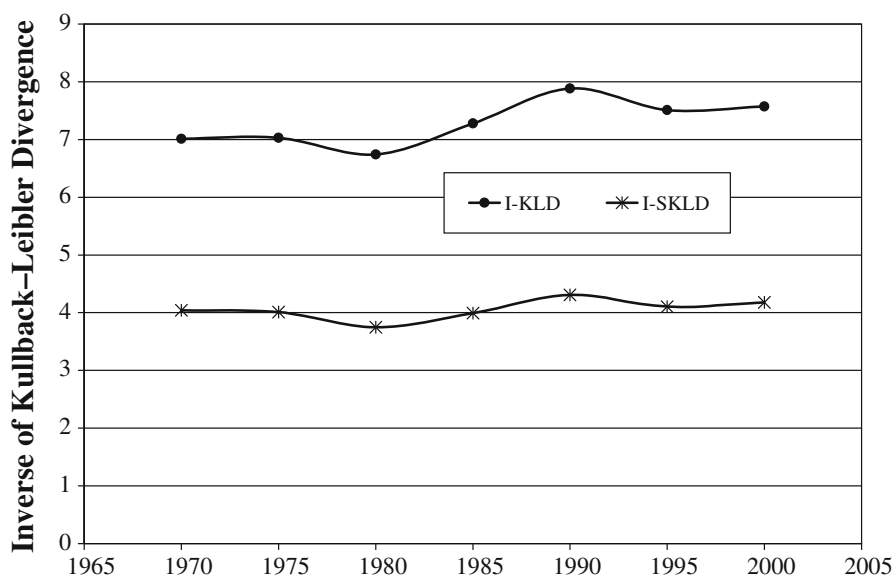

Fig. 4 Trends in integration measures, Latin American Integration Association

among US states remained relatively constant over time, notwithstanding some movement toward less integration in the 1990s as US states gained greater fiscal autonomy implying less fiscal coordination. Figure 3 indicates that the relatively high level of integration of the Andean Community indicated in Table 4 masks a marked decline in its level of integration over time. Similarly, Fig. 7 indicates a general decline in the level of integration among Bangkok Agreement countries. Finally, Fig. 9 indicates that the level of integration of our "world" comprising 64 countries increased only slightly over time. This finding is perhaps surprising, given the common perception that the processes of globalization have meant freer movement of goods and factors among countries. Yet, this result is perhaps less 


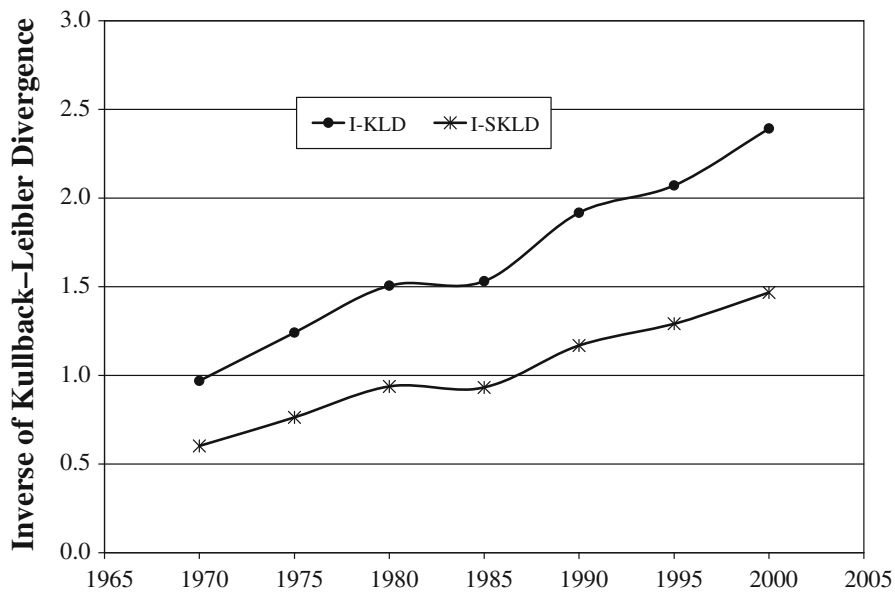

Fig. 5 Trends in integration measures, South African Development Community

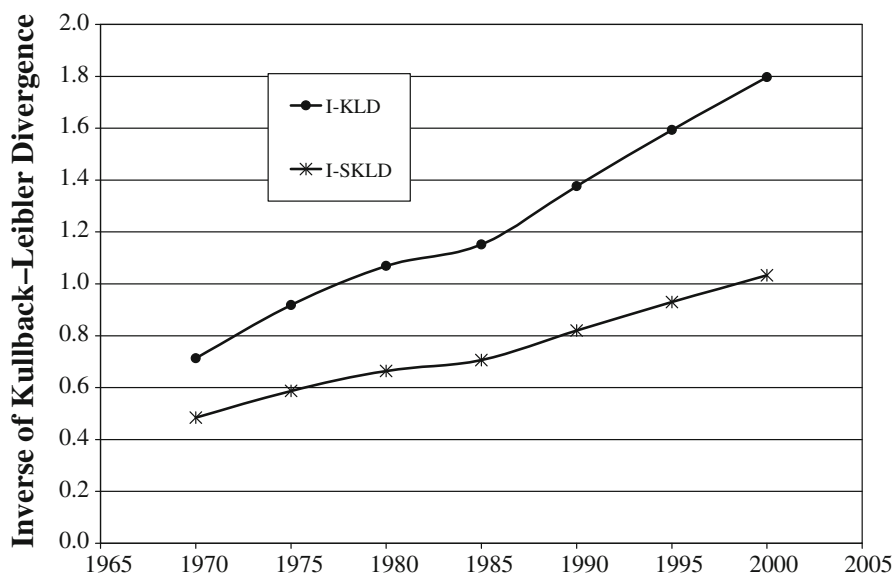

Fig. 6 Trends in integration measures, South African Customs Union

surprising than at first glance, since our theoretical requirements for complete integration include the complete harmonization of social as well as economic policies.

\section{Conclusion}

This paper derived a set of specific relationships expected to arise between economies that are members of a fully integrated economic area (IEA). In this regard, a key relationship expected to hold for any IEA member is the equal-share relationship that links a member's shares of total IEA output and factors supplies. Given the equal-share relationship, it was then demonstrated that complete 


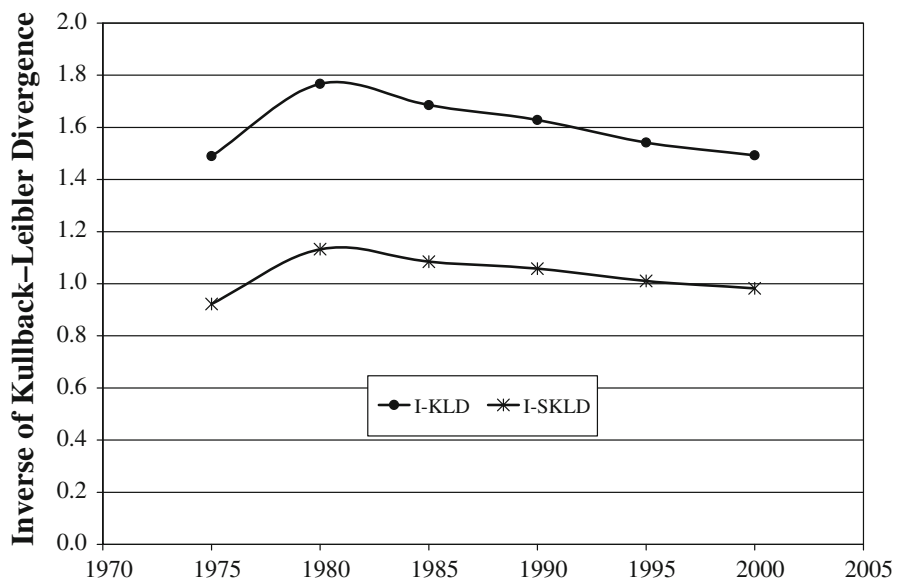

Fig. 7 Trends in integration measures, Bangkok Agreement

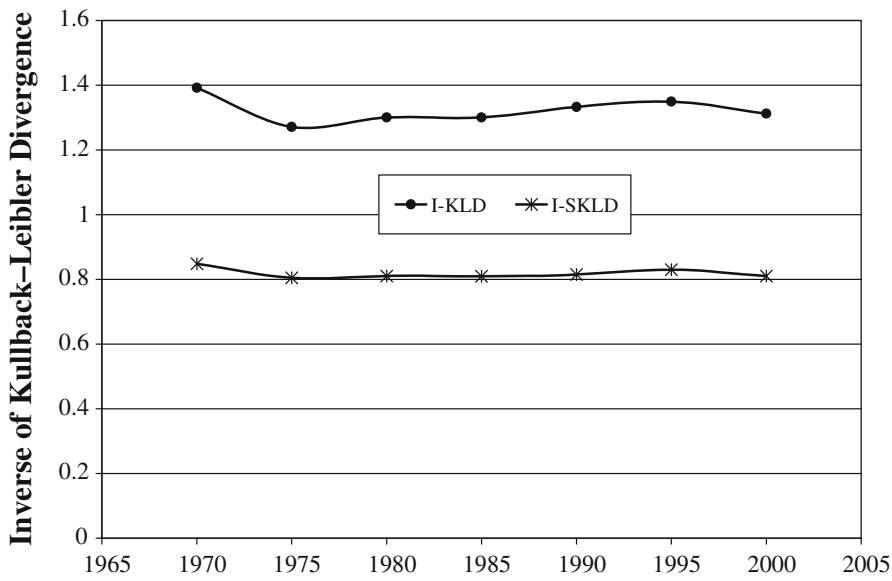

Fig. 8 Trends in integration measures, Southern Common Market (MERCOSUR)

harmonization of economic and social policies across IEA members implied that IEA members output and factor shares would be expected to evolve randomly. The randomness of output and factor shares was then shown to imply that the distribution of each share across IEA members would exhibit Zipf's Law. This result allowed us to develop a method for computing, for any IEA with a fixed number of members, the theoretically expected values of each IEA member's output and factor shares. These theoretical share values were then used along with actual observed share values to derive a measure of the level of integration within any economic group.

For the year 2000, the values of our integration measures indicated that the group comprising of 14 "core" EU countries had the highest level of integration. US states 


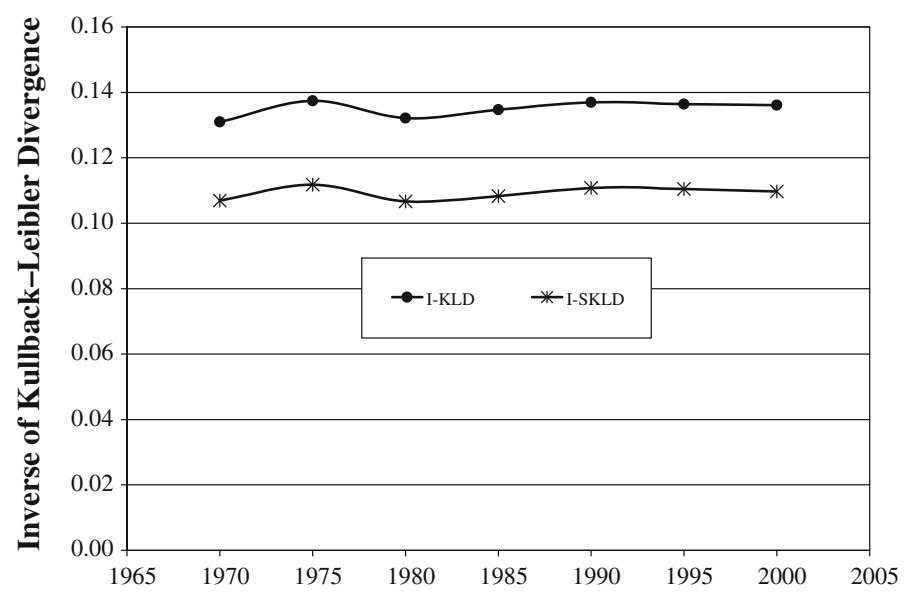

Fig. 9 Trends in integration measures, World-64

had the next highest level of integration, measured to be about $79 \%$ of the integration level of the EU-14 group. The Andean Community ranked third in terms of its level of integration, measured to be about $64 \%$ of the integration level of the EU country group. The remaining country groups all evidenced substantially lower levels of integration, with values of our integration measures at most $41 \%$ of the values obtained for the EU group. The least integrated group was a "world" comprising 64 countries, with a level of integration value only $1 \%$ the level exhibited by the EU group. A surprising finding was that the measured levels integration of our "world" increased only slightly over time. Finally, formal statistical tests for the conformity between the theoretical and actual distribution of shares indicated that, except for the world of 64 countries, in no case could the hypothesis of "full" integration be rejected.

Apart of offering, for the first time, a numerical indication of the degree of integration, perhaps a key contribution of our analysis is to suggest that greater factor mobility and reduced barriers to the flow of goods between countries can be expected to lead to the emergence of the equal-share relationship. The latter, when coupled with harmonized economic and social policies, offers new insights into the distribution of economic activity in an integrated economic area and the relative growth performance of its members.

Acknowledgments We thank Richard Paap and seminar participants at Erasmus, Leuven, Michigan and the Tinbergen Institute for helpful comments and suggestions. We also thank Julia Swart for her very able research assistance. Portions of the paper were written while J. -M. Viaene was visiting the Department of Economics of the University of Michigan, whose hospitality and financial support are gratefully acknowledged.

Open Access This article is distributed under the terms of the Creative Commons Attribution Noncommercial License which permits any noncommercial use, distribution, and reproduction in any medium, provided the original author(s) and source are credited. 


\section{Appendix: Data methods and sources}

\section{US states}

The output for each of the 51 US states is measured by real gross state product as reported by the US Bureau of Economic Analysis (BEA). ${ }^{12}$ These data were available yearly from 1990 to 2000 .

Estimates of state physical capital stocks were derived from BEA (2002) estimates of the total US physical capital stock in each of nine 1-digit industrial sectors comprising all economic activity. ${ }^{13}$ State physical capital stocks were obtained by multiplying each industry's capital stock $^{14}$ by that industry's contribution to state total income and summing the resulting values. ${ }^{15,16}$ For each state, this calculation at time $t$ can be expressed algebraically as

$$
K_{i}(t)=\sum_{j=1}^{9}\left[K_{j}(t)\left(Y_{i j}(t) / Y_{i}(t)\right)\right]
$$

In this equation, $K_{i}(t)$ is the stock of physical capital in state $i, Y_{i j}(t)$ is value added by industry $j$ in state $i(i=1, \ldots, 51), Y_{i}(t)$ is state $i$ 's total value added, and $K_{j}(t)$ is the total U.S. stock of physical capital in industry $j(j=1, \ldots, 9)$. State physical capital stocks were computed annually from the years 1990-2000.

State human capital stocks were derived from data on educational attainment by state taken from the US Bureau. ${ }^{17}$ Since census data on educational attainment are only available every 10 years, data on stocks of human capital were limited to 2 years: 1990 and 2000 .

\section{EU countries (EU-14)}

Total output of each country is measured by real gross domestic product (GDP) computed as the product of real GDP per capita (base year $=1996$ ) and population. Per capita GDP and population data were taken from Penn World Tables 6.1 (Heston et al. 2002). ${ }^{18}$ These data on output cover the period 1960-2000.

Data on physical capital stocks were derived from Penn World Tables 5.6 (Heston and Summers 1991a, b) which reports four data series for each country: (1) population, (2) physical capital stock per worker, (3) real GDP per capita and (4)

\footnotetext{
12 Data on gross state product are available at http://www.bea.doc.gov/bea/regional/gsp.

13 The sectors (BEA code) are Farming (81), Agricultural services, forestry, fishing \& other (100); Mining (200); Construction (300); Manufacturing (400); Transportation (500); Wholesale and retail trade (610); Finance, insurance and real estate (700); and Services (800).

14 Data on state physical capital stocks by industry were taken from US Fixed Assets Tables, available at http://www.bea.doc.gov/bea/dn/faweb.

15 Data on annual state personal income are available at http://www.bea.doc.gov/bea/regional/spi.

16 This procedure follows that used by Munnell (1990) and Garofalo and Yamarik (2002).

17 Decennial Census Dataset are available at http://factfinder.census.gov.

18 Penn World Tables 6.1 is available at http://datacentre2.chass.utoronto.ca/pwt.
} 
real GDP per worker. ${ }^{19}$ Country physical capital stocks were constructed as the product of the first three series divided by the last series. Data cover the period 1965-1990. The capital stock series for each EU country was updated to 2000 using data from Timmer et al. (2003). ${ }^{20}$

Each country's stock of human capital stock was measured by multiplying the percentage of its population aged 15 and over with at least a secondary level of education by the country's total population. Data on rate of educational attainment by country were taken from Barro and Lee (2000). ${ }^{21}$ Data on rate of educational attainment were only available every 5 years, limiting data sample to five-year intervals from 1960 to 2000 .

Other regions (Andean Community, MERCOSUR, LAIA, Bangkok, SACU, SADC)

\section{Output}

Total output of each country is measured by real gross domestic product (GDP) computed as the product of real GDP per capita (base year $=1996)$ and population. Per capita GDP and population data were taken from Penn World Tables 6.1 (PWT 6.1; Heston et al. 2002). ${ }^{22}$ These data cover the period 1960-2000. Missing values for Botswana, Cuba, Laos, Namibia and Swaziland were obtained from Penn World Table 6.2. Missing values for Angola in PWT 6.1 and PWT 6.2 for years 1997-2000 were computed from the World Development Indicators (WDI) database by applying the WDI growth rates of real GDP to the existing real GDP data in PWT 6.1 .

\section{Physical capital}

Country physical capital stocks were computed in three steps. First, for country $n$, real investment in each year was computed using the following formula:

$$
I_{n t}=\left(r g d p l_{n t}\right)\left(k_{n t}\right)\left(\text { pop }_{n t}\right) / 100
$$

Data on the investment share of real GDP $\left(k_{n t}\right)$, real gross domestic product per capita $\left(r g d p l_{n t}\right)$ and total population $\left(\operatorname{pop}_{n t}\right)$ were taken from PWT 6.1. Second, depreciation rates were obtained from PWT 5.6 for the latest year available, 1992, and for the following variables: $15 \%$ for producer durables; $3.5 \%$ for nonresidential construction; $3.5 \%$ for other construction; $3.5 \%$ for residential construction; $24 \%$ for transportation equipment. An overall depreciation rate was then computed as the weighted average of the above depreciation rates with weights being the share of each type of investment in the total. This was done for Malawi, Mauritius, Zambia,

\footnotetext{
19 Penn World Tables 5.6 is available at http://datacentre2.chass.utoronto.ca/pwt56.

20 This physical capital database is available at http://www.ggdc.net/dseries/growth-accounting.shtml.

21 Others studies that have used the Barro-Lee data include, for example, Rajan and Zingales (1998), Ramey and Ramey (1995), Barro (1999), Easterly and Levine (1998), and Hall and Jones (1999).

22 Penn World Tables 6.1 is available at http://datacentre2.chass.utoronto.ca/pwt.
} 
Zimbabwe, Bolivia, Colombia, Ecuador, Venezuela and India. For countries with lacking data on depreciation rates, the average of the depreciation rates of countries in the same trade agreement were used instead. The depreciation rate for Angola, Botswana, Lesotho, Mozambique, Namibia, South Africa, Swaziland and Tanzania is the average of the depreciation rates of Malawi, Mauritius, Zambia and Zimbabwe; the depreciation rate for Argentina, Brazil, Paraguay, Peru, Uruguay and Cuba is the average of the depreciation rates of Bolivia, Colombia, Ecuador and Venezuela; the depreciation rate for Bangladesh, China, Laos, Sri Lanka and Korea Republic is the depreciation rate for India.

Given data on real investment and the rate of depreciation for each county, the stock of physical capital at time $t$ was constructed using the perpetual inventory method:

$$
K_{n t}=\left(1-\delta_{n t}\right) K_{n t-1}+I_{n t}
$$

where $K_{n t}$ is stock of physical capital of country $n$ at time $(t-1), \delta_{n t}$ its depreciation rate, and it is assumed that $K_{n 0}=I_{n 0}$.

For Angola, Botswana, Cuba, Laos, Namibia and Swaziland PWT 6.2 was used to obtain any missing values after conversion to base year 1996. Remaining missing values for Angola from 1997 to 2000 were obtained using United Nations data on Gross Capital Formation (base year $=1990$ ) converted into 1996 values.

\section{Human capital}

Each country's stock of human capital is measured as the product of its population aged 15 and over and the percent of its population aged 15 and over with a secondary level of education. This measure of human capital stock does not account for differences in the quality of schooling across countries. ${ }^{23}$

\section{References}

Andersen, T. M., \& Herbertsson, T. T. (2003). Measuring globalization (Institute of Economic Studies, Working Paper W03:03). University of Iceland, Reikjavik.

Barro, R. J. (1999). Determinants of democracy. Journal of Political Economy, 107, S158-S183.

Barro, R. J., \& Lee, J. W. (1993). International comparisons of educational attainment. Journal of Monetary Economics, 32, 363-394.

Barro, R. J., \& Lee, J. W. (1996). International measures of schooling years and schooling quality. American Economic Review, 86, 218-223.

Barro, R. J., \& Lee, J. W. (2000). International data on educational attainment: Updates and implications (Center for International Development Working Paper 42). Cambridge, MA: Harvard University.

Barro, R. J., \& Sala-ì-Martin, X. (2004). Economic growth. Cambridge, MA: MIT Press.

\footnotetext{
${ }^{23}$ Recent work has sought to improve on international measures of human capital. International test scores of students at primary and secondary levels provide useful information on the quality of education. The International Adult Literacy Survey is a very promising attempt to measure directly the skills of workforce for international comparisons. However, these measures are at present restricted by a limited sample that consists mostly of OECD countries (Barro and Lee 2000).
} 
BEA (US Bureau of Economic Analysis) (2002). Fixed assets and consumer durable goods for 19252001. Washington, DC: US Government Printing Office.

Bhagwati, J. N. (2002). Free trade today. Princeton: Princeton University Press.

Easterly, W., \& Levine, R. (1998). Africa's growth tragedy: Policies and ethnic divisions. Quarterly Journal of Economics, 112, 1203-1250.

Ethier, W. J. (2002). Globalization, globalisation: Trade, technology, and wages (Tinbergen Institute Discussion Paper TI 2002-088/2) Amsterdam.

Gabaix, X. (1999). Zipf's law for cities: An explanation. Quarterly Journal of Economics, 114(4), 739767.

Gabaix, X. (2008). Power laws in economics and finance (NBER Working Paper 14299) Cambridge, MA.

Garofalo, G., \& Yamarik, S. (2002). Regional convergence: Evidence from a new state-by-state capital stock series. Review of Economics and Statistics, 82, 316-323.

Greenaway, D., Lloyd, P., \& Milner, C. (2001). New concepts and measures of the globalization of production. Economics Letters, 73, 57-63.

Hall, R. E., \& Jones, C. I. (1999). Why do some countries produce so much more output per worker than others? Quarterly Journal of Economics, 114, 83-116.

Helpman, E., Melitz, M. J., \& Yeaple, S. R. (2004). Export versus FDI with heterogeneous firms. American Economic Review, 94, 300-316.

Heston, A., \& Summers, R. (1991a). The Penn World Table (Mark 5): An expanded set of international comparisons, 1950-1988. Quarterly Journal of Economics, 106, 327-368.

Heston, A., \& Summers, R. (1991b). The Penn World Table Version 5.6. Center for International Comparisons at the University of Pennsylvania.

Heston, A., Summers, R., \& Aten, B. (2002). The Penn World Table Version 6.1. Center for International Comparisons at the University of Pennsylvania.

Hinloopen, J., \& van Marrewijk, C. (2006). Comparative advantage, the rank-size rule, and Zipf's law (Tinbergen Institute Discussion Paper 06-100/1) Amsterdam.

International Monetary Fund (2004). International financial statistics. Washington, DC: International Monetary Fund.

Khamis, H. J. (2000). The two-stage $\delta$-corrected Kolmogorov-Smirnov test. Journal of Applied Statistics, 27(4), 439-450.

Kullback, S., \& Leibler, R. A. (1951). On information and sufficiency. Annals of Mathematical Statistics, 22, 79-86.

Lau, L., Jamison, D., \& Louat, F. (1991). Education and productivity in developing countries: An aggregate production function approach. Report no. WPS 612, The World Bank, March.

Markusen, J. R. (1983). Factor movements and commodity trade as complements. Journal of International Economics, 14, 341-356.

Mundell, R. (1957). International trade and factor mobility. American Economic Review, 47, 321-335.

Munnell, A. (1990). Why has productivity growth declined? Productivity and public investment. New England Economic Review, (January/ February), 3-22.

Nehru, V., Swanson, E., \& Dubey, A. (1995). A new data base on human capital stock: Sources, methodology, and results. Journal of Development Economics, 46, 379-401.

Rajan, R. G., \& Zingales, L. (1998). Financial dependence and growth. American Economic Review, 88, 559-586.

Ramey, G., \& Ramey, V. A. (1995). Cross-country evidence on the link between volatility and growth. American Economic Review, 85, 1138-1151.

Riezman, R., Whalley, J., \& Zhang, S. (2005). Metrics capturing the degree to which individual economies are globalized (CESifo Working Paper No. 1450) Munich.

Riezman, R., Whalley, J., \& Zhang, S. (2006). Distance measures between free trade and autarky for the world economy (Working Paper, Iowa State University) Munich.

Rodrik, D. (1997). Has globalization gone too far? Washington, DC: Institute for International Economics.

Schreyer, P., Bignon, P.-E., \& Dupont, J. (2003). OECD capital services estimates: Methodology and a first set of results (OECD Statistics Working Paper, 2003/6).

Timmer, M. P., Ypma, G., \& van Ark, B. (2003). IT in the European Union: Driving productivity divergence? GGDC Research Memorandum GD-67, University of Groningen.

World Bank. (2005). Global economic prospects: Trade, regionalism and development. Washington, DC: The World Bank. 